\title{
ENGINEERING, INSTALLATION, TESTING, AND INITIAL OPERATION OF THE DIII-D ADVANCED DIVERTOR
}

\author{
by \\ P.M. ANDERSON, C.B. BAXI, E.E. REIS, \\ M.J. SCHAFFER, and J.P. SMITH
}

This is a preprint of a paper to be presented at the Sixteenth Symposium on Fusion Technology, September 3-7, 1990, in London, England and to be printed in the Proceedings.

\author{
Work supported by \\ U.S. Department of Energy \\ Contract DE-AC03-89ER51114
}

\author{
GENERAL ATOMICS PROJECT 3466 \\ SEPTEMBER 1990
}

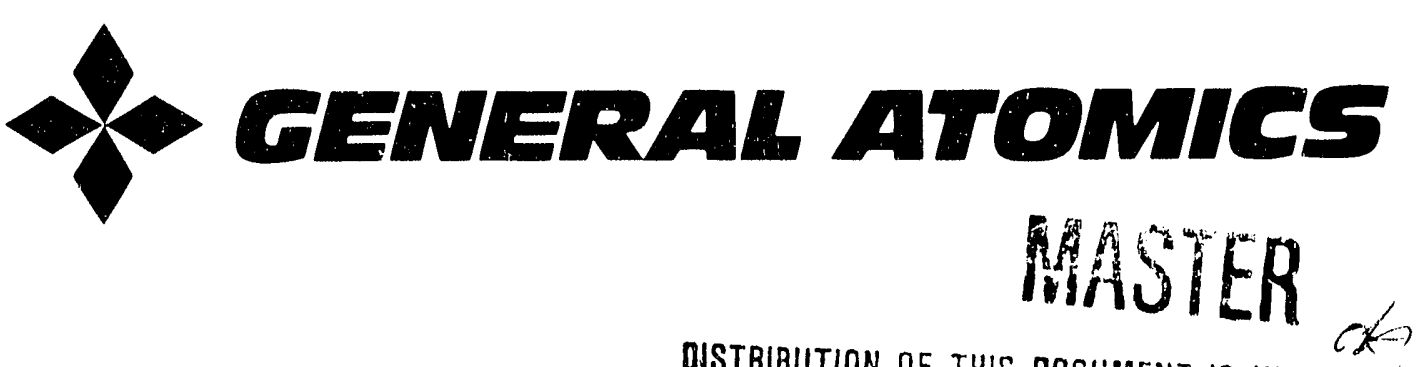




\title{
ENGINEERING, INSTALLATION, TESTING, AND INITIAL OPERATION OF THE DIII-D ADVANCED DIVERTOR
}

\author{
P.M. ANDERSON, C.B. BAXI, E.E. REIS, M.J. SCHAFFER, J.P. SMITH \\ General Atomics, P.O. Box 85608, San Diego, California 92186-9784, USA ...
}

The Advanced Divertor (AD) for General Atomics tokamak, DIII-D, was installed in the summer of 1990 . The $\mathrm{AD}$ has enabled two classes of physics experiments to be run: divertor biasing and divertor baffling. Both are new experiments for DIII-D. The AD has two principal components: (1) a continuous ring electrode; and (2) a toroidally symmetric baffle. The tokamak can be run in bias baffle or standard DIII-D divertor modes by accurate positioning of the outer divertor strike point through the use of the DIII-D control system.

The electrode is a continuous Inconel ring armoured with graphite. It is water cooled during normal operation and bakeable to $350^{\circ} \mathrm{C}$ for vessel conditioning. The electrode is electrically isolated from the vessel wall and is biasable to $1 \mathrm{kV}$ and $20 \mathrm{kA}$. The outer leg of the divertor will be positioned on the graphite covered ring during biasing experiments.

The supports for the ring are radially flexible to handle the differential thermal growth between the ring and the vessel wall, but stiff in the vertical direction to restrain the ring against large disruption forces. Similarly, the coolant and electrical feeds also are flexible in the radial direction but rigidly supported in other directions where they pass outside the toroidal field. All the feeds are supported from and maintain a $5 \mathrm{kV}$ isolation to the vessel wall.

Plasma facing insulators are needed in order to maintain electrical insulation. In addition, all biased surfaces behind and underneath the ring are insulated to prevent breakdown along the field lines. Tests of insulators were made in DIII-D during plasma operations prior to deciding on the final design. Other tests and analyses were performed on insulating materials.

The baffle allows for future installation of approximately 50,000 l/s cryo pumping for particle removal in the outer bottom corner of the vacuum vessel. The strike point will be positioned at the entrance aperture for the baffle mode. The aperture geometry is designed to facilitate a large particle influx with a high probability that backstreaming particles will be reionized and redirected to the aperture.

The paper covers design, analysis, fabrication, installation, instrumentation, testing, initial operation, and future plans for the Advanced Divertor from an engineering viewpoint.

\section{INTRODUCTION}

General Atomics and several collaborators have installed the Advanced Divertor (AD) for the DIII-D tokamah experiment. Primary goals of the program are to obtain $\mathrm{H}$-mode density control for transport and current drive studies, to study effects of edge current on plasma stability, to test de helicity injection steady state current drive, and to study divertor engineering and improvements for future tokamaks such as CIT and ITER.

Two new major components were installed in the tokamak to perform the AD experiments (Figure 1). The first is an electrically isolated toroidal continuous ring electrode in the outer lower divertor region that will be powered up to $1 \mathrm{kV}$ and $20 \mathrm{kA}$. The second major addition is a toroidally continuous gas baffle between the outer wall and the biased ring. The volume created behind the toroidal baffle will be equipped with a cryogenic pump ( $>50,000 \mathrm{l} / \mathrm{s}$ ), planned for installation in mid-1991. Either divertor bias or divertor baffle modes can be run by acljusting the position of the outer divertor strike point using the field shaping coils. In the bias mode, an external power supply will drive up to $20 \mathrm{kA}$ into the scrape-off layer, allowing experiments to study particle transport modification, second stability limits, and helicity injection current drive. Current will return to the vessel through the inner divertor strike point with single null divertors, or to the outer upper strike point with double nulls. The baffle mode will test density control, particle exhaust and tokamak operation with net particle throughput. Finally, by moving the lower divertor outer ecrike point further inward, the plasma can be removed from interaction with the AD. The entire AD system was designed for minimal intrusion on 

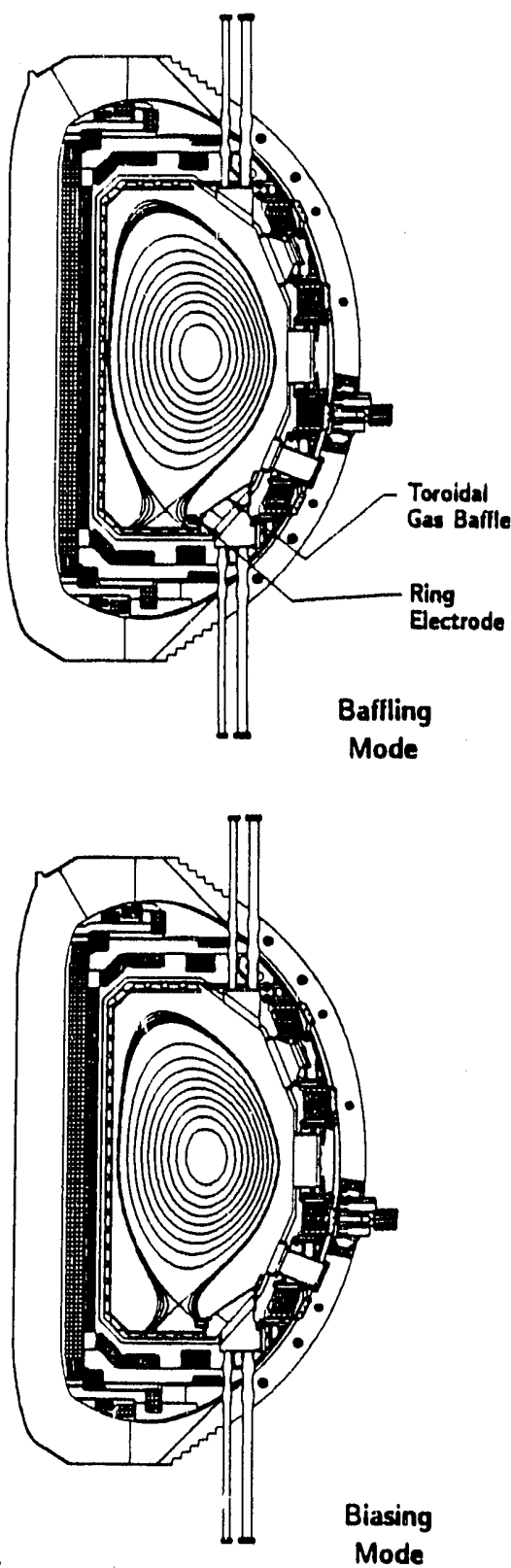

FIGURE 1.

Operation modes of Advanced Divertor.

the plasma volume and minimal limitations on normal plasma operation.

\section{RING}

The toroidally continuous ring is made of Inconel 625 for its strength, relatively high electrical resistivity, and high temperature capability. The ring has two parallel coolant channels machined and welded into it. This coolant channel is connected to the same air/water system as is used in the walls of the DIII-D vessel. During bakeout, hot air flows through the channels, while water flows during operation. The air does not provide much cooling to the ring during bakeout, but during operation the water is necessary to keep the temperature of the ring below $100^{\circ} \mathrm{C}$ to limit the differential thermal expansion of ring as compared to the vessel. ${ }^{1}$

The graphite tile is made of the same basic design and material and uses the same mounting configuration as the vessel armor tile. ${ }^{2}$ Thermal and stress analysis was performed for the graphite tile. ${ }^{1}$

The ring is supported off the vessel floor by 24 local Inconel 625 brackets (Figure 2). During bakeout, there is a calculated transient temperature difference between the vessel and the ring of up to $72^{\circ} \mathrm{C}$. The supports are sufficiently flexible in the radial direction to accommo date the differential thermal growth, but strong enough to withstand the predicted disruption load of $12 \mathrm{kNt} / \mathrm{m}$.

Disruption loads were analyzed for the continuous ring. The standard disruption loads from induced toroidal current scale with the cross sectional area of the Inconel ring (resistive limit), Recent theory and obser: vation show that there is also a large poloidal current flow in the plasma edge during distuptions. This currrent is kept from flowing into the electrode by a $1 \mathrm{mH}$ external inductance. The disruption forces acting on the ring are estimated to be $12,000 \mathrm{~N} / \mathrm{M}$ and are analyzed to act in any direction. The supports are stiff in the vertical direction to manage these large vertical loads. The radial loads caused by disruptions are reacted internally by the ring, with the ring having a factor of safety of over five for out of plane buckling. To insulate the biasable ring from the vessel wall, an insulated bolt system is used at the ring support joint.

In order to install the ring through one of the large midplane ports, four 90-degree segments are assembled inside the vessel wilh bolis and shear pins.

Each section of the ring has an independent cooling circuit with an inlet at one end and the outlet at the other (Figure 3). The fluid connections and electric feed connections are made at four equally spaced locations $n$ the ring. The fluid flows through $2 \mathrm{~cm}$ Inconel tubing. The 5000 amp feed current passes through a rectangular copper bar that is cooled by contact with the water cooled ring and port flange. These feed lines route through electrically isolated port flanges which art. 


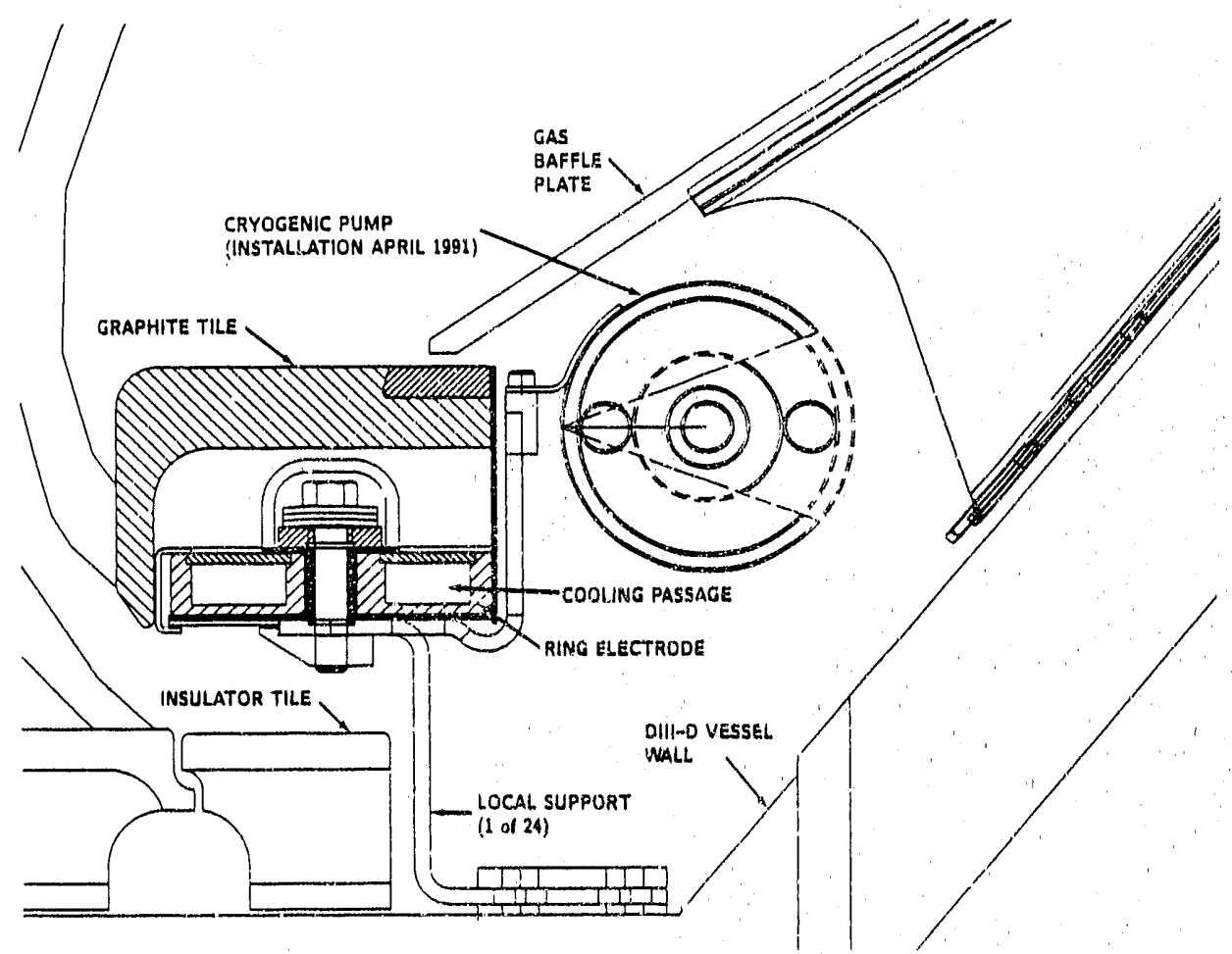

FIGURE 2.

Key componante of Advanred Divertor.

also used for routing of ring mounted Langmuir probes and thernocouples.

\section{INSULATORS}

Two plasma-facing cross-field insulator rings are required to prevent arcs along magnetic lines to the vessel. The first insulator riag is on the floor of the vesoel. It provides electrical insulation against current Dow along magnetic field lines from the clectrode to the vessel floor. 'The geometry is suab thot field lines at angles of $45 \pm 10$ degrees off the lower inside corver of the electrode are flanked by $1 \mathrm{~cm}$ of cross field insulation sloug; the top surface of the floor insulator. The design of the floor insulater tile is the same as the graphite floor tile it replaced, except it is shorter poloidally. The upper ring of small insulator tiles provides $1 \mathrm{~cm}$ of cross field insulation between the electrode and the baffle plate. Both insulators are machined from Union Curbide HBC boron nitride (BN). The selection of this garle of $B N$ was based in thermal shock testing and analysis.

The outer and hottom surfaces of the ring electrode are covered with multiple layers of Mica Mat plate, an inorgarically bonded mica product. On the bottoin of the ring, the beat losd is large enough to require an alunnina beat shield over the Mica Mat. The cooling and electric feed lines are electrically insulated with braicled Nextel siecving and a grounded foil oyerwrap.

\section{BAFFLE}

The baffe traps neutrals behind the ring and limits their recycling back into the plasma. The entrance aperture is $30 \mathrm{~km}$ high, It was designed for $50,000 \mathrm{l} / \mathrm{s}$ pumping speed sging the DEGAS code. The modeling and pumping analysis was done by Oak Ridge National Laboratory. Leakage of $5000 \mathrm{l} / \mathrm{s}$ from all baflle joints was allowed. A cryogenic puosp (Figure 4) will be installed in 1991.

The baffle is made up of 24 individuai $0.8 \mathrm{~mm}$ thick Inconel plates supported off the vessel wall. They extend from the ring to the outer wall of the vacuum vessel (Figure 5). Component joints are sealed by thin stainless steel and Mica Mat strips. Large polcidel currents can flow through the plates and their supports to the vessel wall during disruptions, gerserating a 2.5 atm 


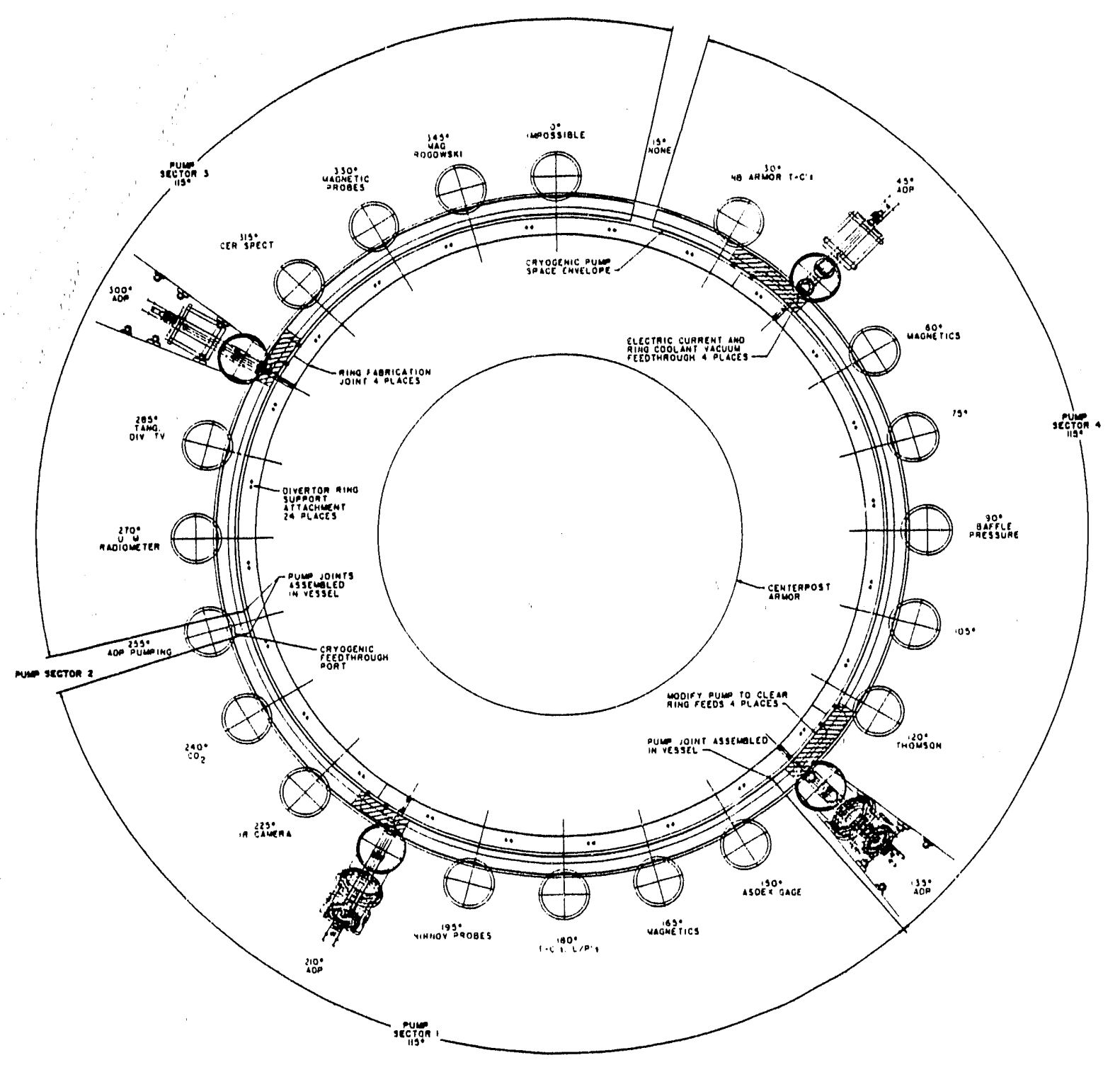

FIGURE 3.

Plan view of Advanced Divertor and water and electrical feeds.

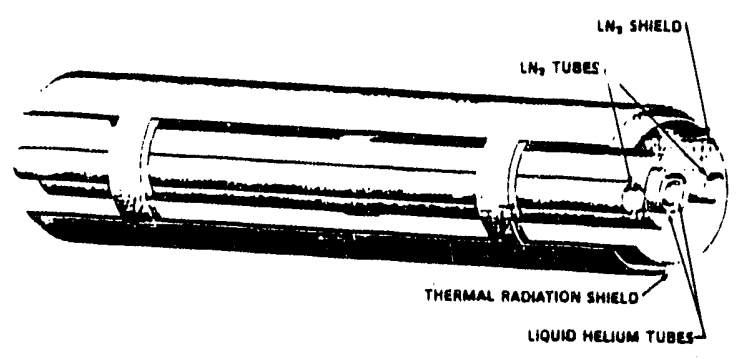

FIGLRE 4.

Advanced Divertor Pumping. pressure loading on the plates. Diagnustics penetrations through baffle plates were sealed by local shrouds with low gas conductance gaps where electrical paths had to be broken.

Thermal analysis of the plates concluded that during bakeout, the plates will be heated inductively to a temperature of $425^{\circ} \mathrm{C}$ while the vessel is at $400^{\circ} \mathrm{C}$. The bafflo plate temperature will lead the vessel wall temperature on heat up creating a maximum $\Delta T$ of $200^{\circ} \mathrm{C}$. During operation the plates reach a higher temperature of $300^{\circ} \mathrm{C}$, and the supports to the vessel wall 


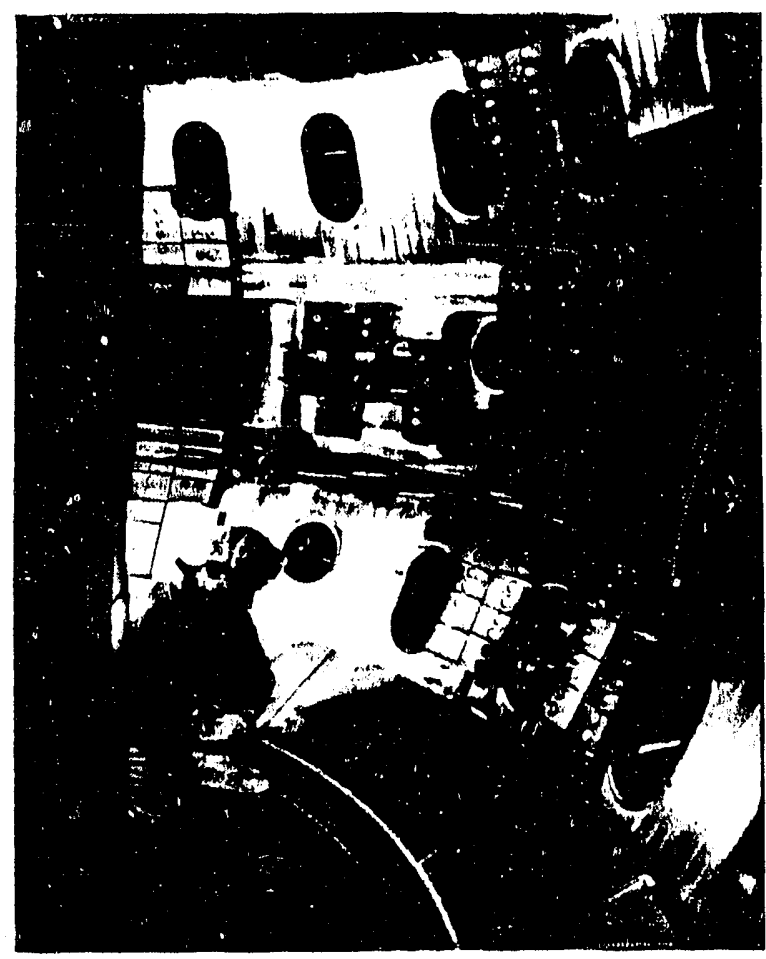

FIGURE 5

Installation photo.

are designed to allow for the differential thermal growth between the cold vessel wall and the hotter baffle plates.

The baffle insulator ring previously mentioned is supported from the graphite tiles mounted on the ring.

\section{TESTING}

Many new materials were proposed throughout the design of the $A D$ and a testing program was implemented to evaluate the materials. Heat flux tests, outgassing tests, and electrical tests were performed.

Sandia National Laboratories, Albuquerque (SNLA) conducted heat flux tests using an electron beam to thermally shock candidate materials. T'he best grade of boron nitride tested withstood at least 2.5 times higher heat flux than the candidate silicon carbicle insulator. In addition, boron nitride failed "softly" by sublimation, whereas the silicon carbide failed catastrophically by shattering. These results led to the selection of boron nitride as the material for plasma facing insulators.
Sandia National Laboratories Livermore performed outgassing tests for all proposed new vacuum materials. The materials were tested in a vacuum test chamber and the pressure and residual gas monitored. Temperalures of the test runs were chosen to simulate temperatures seen in the vessel. The data were then evaluated to determine if the outgassing is within acceptable limits for use inside DIII-D.

Electrical testing was done at General Atomics. Tests were done in vacuum, gas and glow discharge environments to design the Nextel and metal foil flexible insulation system for the fluid and electrical feeds and instrumentation cable bundles. Insulator tests were done in DIII-D to measure cross field insulation of both smooth and groove surfaces. No difference was observed. A test was also made on a prototype insulated support joint. In this test, one side of the joint was biased up to $5 \mathrm{kV}$ without breàkdown. Mechanical load testing of the insulated joint was also performed.

The installed system was biased to $1.2 \mathrm{kV}$ in air after assembly into the vessel with a resistance to ground of about $50 \mathrm{k}$ ohms.

\section{DIAGNOSTICS}

Tile current monitors that measure the current flowing from the scrape off layer to the vessel, ring mounted Langmuir probes, pressure gages in the baffled volume and a visible spectrometer viewing the plasma strike zone below the divertor ring were added to study plasma performance with the AD. Two reciprocating fast probes will also be installed. Installation of the biased ring and baffles was completed in August 1990.

\section{ACKNOWLEDGEMENTS}

The work was sponsored by the U.S. Department of Energy under Contract No. DE-AC03-89-EF51114.

\section{REFERENCES}

1. C.B. Baxi, et al., "Thermal Design and Analyses of DIII-D Advanced Divertor," in Proceedings of the Thirteenth Symposium on Fusion Engineering, IEEE, Cat. No. 89CH2820-9, pp. 951-954.

2. J.P. Smith, et al., "Design of DIII-D Armor Tiles," in Proceedings of the Twelfth Symposium on

Fusion Engineering, IEEE Cat. No. 87CH2507-2, pp. 144-146. 

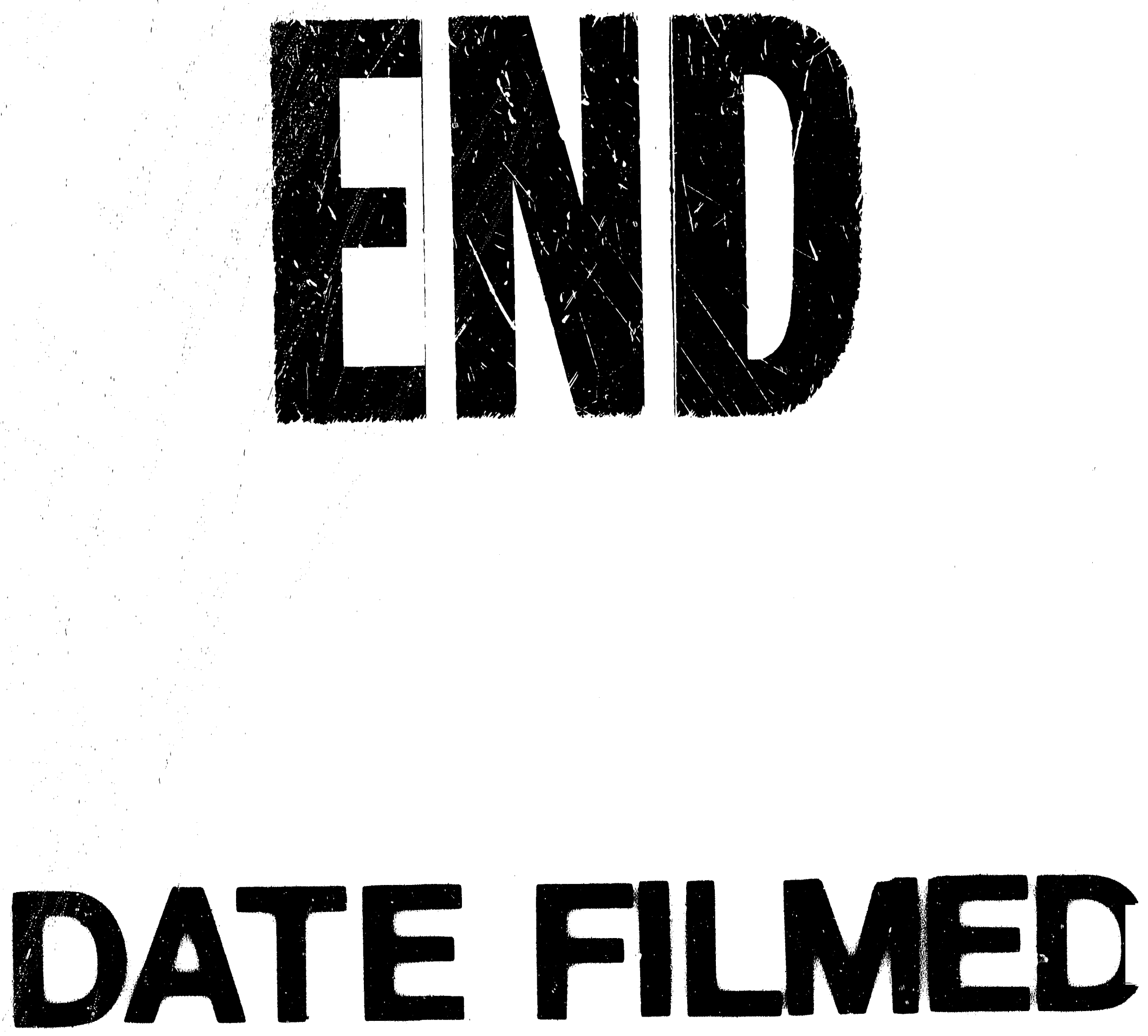

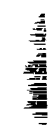
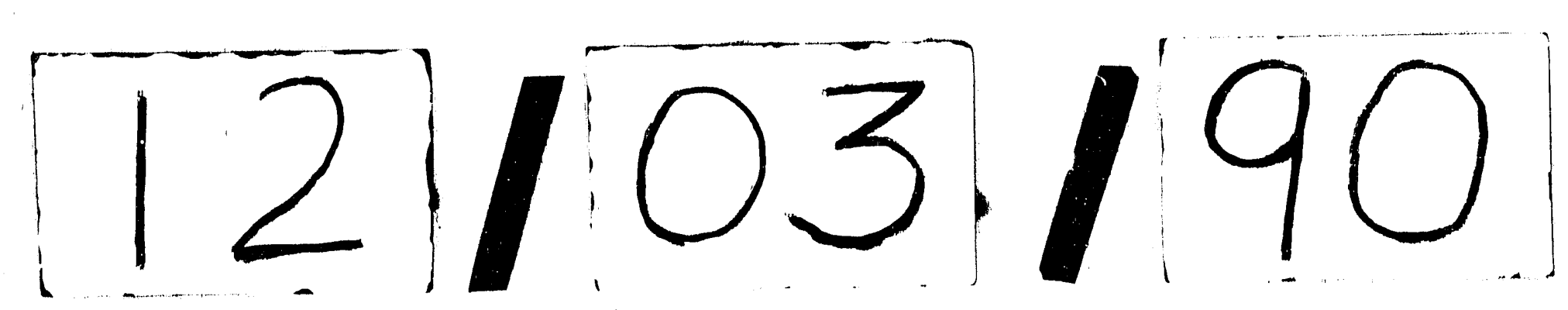
